\title{
MEDIA PENUNJANG INFORMASI DAN PROMOSI BERBENTUK KATALOG PRODUK PADA PT. IDEAL FORMICA PURNATATA TANGERANG
}

\author{
Alin Parlina ${ }^{1}$ \\ Gita Mawarni $^{2}$ \\ Dinda Safitri ${ }^{3}$ \\ Mahasiswa STMIK Raharja Jurusan Teknik Informatika ${ }^{1,2,3}$ \\ Jl. Jendral Sudirman No. 40, Modern Cikokol, Tangerang ${ }^{1,2,3}$ \\ Email: alin@raharja.info ${ }^{1)}$, gita.mawarni@raharja.info ${ }^{2)}$,dinda@raharja.info ${ }^{3)}$
}

\begin{abstract}
ABSTRAK
Media komunikasi visual berperan penting dalam pengenalan diri sebuah perusahaan terutama dalam menunjang informasi dan promosi. Salah satu media komunikasi visual yang sangat penting dalam menunjang keberhasilan promosi perusahaan adalah media katalog produk.Perusahaan membutuhkan media informasi dan promosi berupa media cetak, karena media tersebut efektif di banding dengan media lainnya seperti video profile. PT. Ideal Formica Purnatata adalah perusahaan yang bergerak di bidang pembuatan produk-produk interior dan arsitektural. Tujuan dari penelitian ini, agar perusahaan dapat mencapai target penjualan dari setiap produk yang dipasarkan. Untuk mendapatkan data yang akurat dalam penyusunan penelitian, terdapat metodologi penelitian yang digunakan yaitu : metode analisa permasalahan, metode pengumpulan data, metode analisa perancangan dan metode konsep desain. Permasalahan yang ada yaitu minimnya media informasi dan promosi seperti media katalog produk.Media komunikasi visual ini mempunyai metode perancangan salah satunya berupa material yang digunakan yaitu art carton 260 gr dan art paper 120 gr. Pemilihan material ini di gunakan karena bahan yang sesuai dengan media katalog. Melalui perancangan media katalog produk, diharapkan dapat meningkatkan daya tarik konsumen untuk menggunakan jasa dan produk PT. Ideal Formica Purnatata, sehingga target penjualan tercapai, omset perusahaan meningkat, dan PT. Ideal Formica Purnatata dikenal secara luas.
\end{abstract}

Kata Kunci : Media komunikasi visual, media promosi dan informasi, katalog produk

\begin{abstract}
Visual communications media plays an important role in the self-introduction a company primarily in supporting information and promotion. One of the visual communication media is very important in supporting the successful sale of the company is a media product catalog. Companies in need of information and promotional media such as print media, because the media is effective compared with other media such as video profile. PT. Ideal Formica Purnatata is a company engaged in the manufacture of products and architectural interiors. The purpose of this study, so that the company can achieve its sales target of each product marketed. To obtain accurate data in the preparation of the study, there is the research methodology used are: problem analysis methods, data collection methods, methods of design analysis and methods of design concepts. The problem that exists is the lack of information and promotional media such as media product catalog. Visual communication media has a method of designing one form of material used is $260 \mathrm{~g}$ carton art and art paper $120 \mathrm{gr}$. The choice of material is in use because of the materials according to the media catalog. Media design through product catalogs, is expected to increase the attractiveness of the consumer to use the services and products of PT. Ideal Formica Purnatata, so that the sales target is reached, the company's turnover increased, and PT. Ideal Formica Purnatata widely known.
\end{abstract}

Keywords: Media visual communication, media promotion and information, catalog product 


\section{PENDAHULUAN}

Media komunikasi visual merupakan suatu bentuk komunikasi dengan menggunakan desain grafis yang didalamnya terdapat unsur tipografi, fotografi, dan ilustrasi. Perkembangan media informasi dan promosi yang semangkin modern mempengaruhi sistem promosi sebuah perusahaan. Modern yang dimaksud dalam hal ini adalah hal-hal yang berkaitan dengan desain yang dibuat menarik dan menggunakan data yang up to date. Media promosi sendiri sangat berpengaruh pada sejumlah perusahaan termasuk perusahaan yang menjalankan bisnis dibidang pembuatan produk-produk interior dan arsitektrual. Berbagai cara dapat dilakukan oleh perusahaan untuk terus mengembangkan setiap produk yang dihasilkan.

Dalam hal ini setiapperusahaan harus memiliki media informasi dan promosi yang menarik sehingga mampu dikenal masyarakat luas secara positif, bahkan terlebih lagi perusahaan berharap masyarakat tersebut menjadi pengguna jasa atau produk yang ditawarkan. Berbagai upaya dilakukan oleh perusahaan untuk mencapai hal tersebut, dan kegiatan yang paling berperan serta adalah promosi. Promosi sebuah perusahaan yang direncanakan dengan baik dan matang akan menghasilkan keuntungan bagi perusahaan. Contoh dari media promosi yang dimaksud berupa brosur, leaflet, spanduk, baliho, kartu nama, booklet, seragam dan lain sebagainya. Akan tetapi dari semua contoh di atas bentuk dari media yang paling tepat untuk mempromosikan produk-produk perusahaan yaitu media katalog produk, karena katalog produk merupakan media komunikasi visual yang dinilai efektif dalam menyampaikan informasi dan promosi serta dapat mengenalkan kualitas, kegunaan, gambar, dan keunggulan dari produk yang dihasilkan oleh PT. Ideal Formica Purnatata.

PT. Ideal Formica Purnatata adalah perusahaan yang bergerak dibidang pembuatan produk-produk interior dan arsitektural dengan laminasi berkualitas seperti panel, furniture dan kabinet. Perusahaan ini didirikan sejak tahun 1993 dan sekarang berada di Kota Tangerang yang beralamat di Jl. KH. Hasyim Ashari Km.2 No.81 Kecamatan Cipondoh Tangerang Banten. Semua hasil dari produksi yang ada sangat disayangkan jika tidak diimbangi dengan media komunikasi visual yang menarik untuk menginformasikan dan mempromosikan perusahaan.

Berdasarkan hasil wawancara dan analisa kebutuhan dengan stakeholder pada PT. Ideal Formica Purnatata, saat ini divisi pemasaran masih menggunakan media promosi berupa portofolio sederhana saja dalam melakukan presentasi kepada klien, sehingga hal ini menjadi peluang untuk merancang desain promosi, melalui media katalog produk. Desain pada media promosi dapat mempengaruhi minat jumlah pengguna jasa PT. Ideal Formica Purnatata, semakin menarik desain yang dibuat, semakin jelas informasi yang disampaikan, semakin banyakpula calon konsumen yang tertarik pada produk PT. Ideal FormicaPurnatata.

Untuk itu PT. Ideal Formica Purnatata sangat membutuhkan media katalog produk, untuk meningkatkan jumlah konsumen dan klien, sehingga tertarik pada produk-produk furniture yang dipasarkan oleh PT. Ideal Formica Purnatata, agar dalam pelaksanaan programpromosi dapat berjalan dengan baik, maka segala sesuatunya harus dipersiapkan dengan matang oleh PT. Ideal Formica Purnatata. 


\section{PERMASALAHAN}

Media informasi dan promosi yang terdapat pada media komunikasi visual yang digunakan saat ini pada divisi pemasaran PT. Ideal Formica Purnatata masih menggunakan media promosi berupa portofolio sederhana saja. Pihak perusahaan menginginkan adanyabuku katalog produk yang berisi keterangan informasi jenis produk, keunggulan, dan harga, yang nantinya akan digunakan pihak pemasaran pada saat mempromosikan produknya kepada konsumen, klien tetap, relasi perusahan, dan instansi pendidikan. Selain itu media katalog produk ini, diharapkan dapat menjadi solusi untuk meningkatkan cara promosi dan informasi kepada konsumen danrelasi perusahaan, dimana katalog produk ini akan dipakai oleh bagian pemasaran dalam mempresentasikan produk-produk furniture yang diproduksi kepada setiap konsumen dan relasi perusahaan yang datang. Berikut beberapa permasalahan yang ada pada PT. Ideal Formica Purnatata yaitu:

1. Jenis media apa yang dibutuhkan PT. Ideal Formica Purnatata untuk meningkatkan penjualan?

2. Dari perancangan media yang dihasilkan target seperti apa yang diinginkan oleh PT. Ideal Formica Purnatata?

3. Bagaimana cara merancang media yang mempunyai nilai daya tarik kepada konsumen?

\section{LITERATURE REVIEW}

1. Penelitian yang dilakukan oleh Sumaryani, $2014^{[14]}$ dari Perguruan Tinggi Raharja yang berjudul "Perancangan Media Katalog Sebagai Penunjang Informasi dan Promosi pada CV. Zero Store" Media katalog adalah sebuah karya desain yang digunakan untuk meningkatkan suatu image atau citra dari perusahaan, maka dari itu CV. Zero Store membutuhkan media katalog sebagai media informasi dan promosi.

2. Penelitian yang dilakukan oleh Palupi, 2014 ${ }^{[10]}$ dari Perguruan Tinggi Raharja yang berjudul "Perancangan Media Komunikasi Visual Berbentuk Katalog Produk Sebagai Media Promosi di PT. Anugerah Duta Pratama Jakarta". Salah satu cara untuk mempromosikan suatu produk adalah dengan menggunakan media komunikasi visual berbentuk katalog yang secara tidak langsung dapat diharapkan nilai efektifitasnya dalam mengkomunikasikan progam-progam pemasaran produk PT. Anugerah Duta Pratama.

3. Penelitian yang dilakukan oleh Suprian, 2012 ${ }^{[17]}$ dari STMIK Yogyakarta yang berjudul "Perancangan Aplikasi Katalog Interaktif Sebagai Media Promosi pada Butik Busana Sunnah Banjarmasin Berbasis Multimedia". Salah satu teknologi di bidang informasi adalah multimedia. Multimedia adalah salah satu cara untuk memudahkan penyampaian informasi tertentu dalam bentuk visual, kehadiran multimedia telah mengubah cara orang berinteraksi dengan komputer melalui media gambar, teks, audio, animasi, dan video. Latar belakang masalah ini kemudian dibuat untuk membuat media promosi berbentuk katalog.

4. Penelitian yang dilakukan oleh Munawar, 2013 ${ }^{[9]}$ dari Perguruan Tinggi Raharja yang berjudul "Perancangan Media Desain Katalog Produk di PT. Utama Mandiri Jaya". Perusahaan-perusahaan saling bersaing untuk meningkatkan profitnya berbagai informasi dan promosi di galakan untuk menarik kepercayaan masyarakat, namun tanpa didasari informasi yang komplit dan terpecaya mengenai profil perusahaan PT. Utama Mandiri 
Jaya yang belum di ketahui masyarakat maka dari itu PT. Utama Mandiri Jaya mengembangkan media promosi dengan menggunakan media katalog.

5. Penelitian yang dilakukan oleh Hidayah, $2014^{[6]}$ dari Universitas Semarang yang berjudul "Perancangan Katalog Studio Seni FBS UNNES". Proses berkarya dalam pembuatan desain katalog ini adalah meliputi penetapan tujuan karya, analisis target, studi kepustakaan, metode wawancara, penentuan konsep desain, pengambilan objek, seleksi pengambilan objek, pembuatan secara komputerisasi, konsultasi dosen, percetakaan,penyajian karya desain, dan reprografis.

6. Penelitian yang dilakukan oleh Fawzia, $2012^{[4]}$ dari Universitas Airlangga yang berjudul "Pengetahuan Konsumen Tentang Katalog Oriflame sebagai Media untuk Memasarkan Produk". Penelitian bertujuanuntuk menggambarkan bagaimana pengetahuan konsumen tentang katalog Oriflame sebagai media untuk memasarkan produk. Ketertarikan konsumen untuk membeli pun bisa juga dikarenakan media katalog cetak ini, mengingat perusahaan Oriflame tidak menyediakan toko. Penelitian merupakan kuantitatif dan deskriptif. Dengan purposive sampling, penentuan responden berdasarkan karakterkarakter yang relavan.

7. Penelitian yang dilakukan oleh Prasetyo, 2013 ${ }^{[11]}$ dari AMIKOM Yogyakarta yang berjudul "Perancangan Katalog Online Berbasis Website sebagai Media Promosi dan Informasi Pada Twenty One Computer". Twenty One Computer merupakan salah satu toko komputer yang berada di kota kabupaten Temanggung yang menjual berbagai macam hardware komputer. Toko ini belum lama berdiri sehingga media promosi yang digunakan oleh toko ini masih menggunakan media promosi radio dan penyebaran brosur. Oleh karena itu dibutuhkan media promosi yang dapat menyajikan informasi, detail barang yang ditawarkan danpromo yang diberikan oleh toko seperti katalog.

8. Penelitian yang dilakukan oleh Akbar, 2013 ${ }^{[1]}$ dari Mercu Buana yang berjudul "Perancangan Media Komunikasi Visual Katalog sebagai Sarana Promosi Rvins Jeans". Media katalog ini merupakan wujud aplikasi dalam mempromosikan produk rvins jeans yang merupakan perusahaan celana jeans, diharapkan dapat menarik konsumen. Tujuan perancangan promosi rvins jeans melalui media komunikasi visual katalog adalah untuk promosi yang tepat pada perusahaan yang bergerak dibidang fashion yang berfokus kepada celana jeans di Rvins Jeans Bandung.

9. Penelitian yang dilakukan oleh Satrio, 2012 ${ }^{[13]}$ dari Universitas Negeri Malang yang berjudul "Perancangan Katalog Wisata Kota Surabaya sebagai Media Informasi Massa". Tujuan Perancangan Katalog Wisata Kota Surabaya Sebagai Media Informasi Massa ini adalah mempromosikan tempat-tempat wisata yang terdapat di Kota Surabaya kepada masyarakat luas tidak hanya yang berada di Surabaya saja, tetapi juga wisatawan lokal dan luar negeri. Memberikan informasi secara mudah dan praktis untuk bisa mengetahui dan menikmati dengan baik dan nyaman segala macam wisata yang ditawarkan di Kota Pahlawan Surabaya baik itu sarana transportasi maupun fasilitas yang terdapat di tempattempat wisata tersebut.

10. Penelitian yang dilakukan oleh Hakim, 2015 ${ }^{[5]}$ dari STMIK Provinsi Semarang yang berjudul "Perancangan Katalog Digital pada UMKM Sentra Bordir Desa Padurenan Kudus". Perancangan katalog digital pada UMKM sentra bordir desa padurenan kudus 
maka UMKM mampu meningkatkan peluang dengan menyatukan katalog digital dengan website e-commerce, mengembangkan aplikasi berbasis tablet, handphone, ditambah dengan fitur email marketing dan penguatan pelung transaksi dengan calon konsumen.

\section{LANDASAN TEORI}

\section{Pengertian Informasi}

Menurut Sunarya, dkk $(2013: 81)^{[16]}$ informasi adalah data yang telah diproses kedalam suatu bentuk yang mempunyai arti bagi si penerima dan mempunyai nilai nyata dan terasa bagi keputusan saat itu atau keputusan mendatang.

McLeod menuliskan bahwa(2012:8) ${ }^{[8]}$ Informasi (information) dapat diartikan sebagai data yang diolah menjadi bentuk yang lebih berguna dan lebih berarti bagi yang menerimannya, informasi disebut juga data yang diproses atau data yang memiliki arti.

\section{Pengertian Media}

MenurutMaimunah,dkk(2012:284) $)^{[7] " M e d i a ~ a d a l a h ~ s a r a n a ~ u n t u k ~ m e n y i m p a n ~ p e s a n ~}$ atau informasi kepada publik dengan menggunakan berbagai unsur komunikasi grafis seperti teks atau gambar atau foto".

MenurutRahardja,dkk(2011:133) ${ }^{[12]}$ "Media adalah saluran penyimpanan pesan komersial kepada khalayak sasaran atau dapat dikatakan salah satu komunikasi periklanan yang dilakukan melalui saluran media tertentu, seperti televisi, surat kabar, majalah, radio, internet, buku profil, media luar ruangan, iklan transit dan direct email".

\section{Pengertian Promosi}

Menurut Budiarto(2011:57) ${ }^{[2]}$ promosi adalah suatu bentuk kegiatan yang diselenggarakan oleh pihak pemasar yang bertujuan untuk menarik perhatian masyarakat, sehingga tertarik untuk melakukan transaksi seperti yang diinginkan oleh pihak pemasar, agar dalam pelaksanaan program promosi dapat berjalan dengan baik, dan segala sesuatunya harus dipersiapkan dengan matang.

Daryanto menuliskan bahwa (2011:23) ${ }^{[3]}$ promosi adalah arus informasi atau persuasi satu arah yang dibuat untuk mengarahkan seseorang atau organisasi kepada tindakan yang menciptakan pertukaran dalam pemasaran.

\section{Pengertian Desain Komunikasi Visual}

Menurut Sunarya, dkk (2015:79) $)^{[15]}$ media komunikasi visual adalah sarana untuk penyampaian pesan atau informasi kepada public yang dirangkai dengan penggunaan media penggambaran yang hanya dapat terbaca oleh indera penglihatan.

Menurut Tinarbuko (2015:77) ${ }^{[18]}$ desain komunikasi visual adalah ilmu yang mempelajari konsep komunikasi dan ungkapan daya kreatif, yang diaplikasikan dalam berbagai media komunikasi visual dengan mengelolah elemen desain grafis terdiri dari 
gambar (ilustrasi), huruf, warna, komposisi, dan layout. Semuanya itu dilakukan guna menyampaikan pesan secara visual, audio, dan audio visual kepada target sasaran yang dituju.

\section{PEMBAHASAN}

\section{Perancangan Media}

Media yang digunakan sebagai media penunjang informasi dan promosi tentang produk furnitur PT. Ideal Formica Purnatata adalah media katalog produk furnitur untuk setiap produk furnitur yang diproduksi oleh PT. Ideal Formica Purnatata. Media katalog produk ini juga selain berisikan gambar produk, media ini juga menampilkan beberapa informasi tentang tips, ide, kualitas dan harga dari produk yang akan ditampilkan di dalam media katalog produk furnitur PT. Ideal Formica Purnatata.

\section{Konsep Kreatif}

Konsep kreatif yang akan ditampilkan kedalam media katalog produk furnitur adalah dengan menampilkan visual yang lebih mengarah kepada furnitur sesuai dengan PT. Ideal Formica Purnatata sebagai perusahaan yang bergerak dibidang furnitur. Desain juga disertai dengan logo PT. Ideal Formica Purnatata, gambar dan alamat, serta terdapat teks yang menarik dan sudah disesuaikan penempatannya untuk menginformasikan isi dari setiap desain, selain itu warna yang di tampilkan secara mayoritas yaituwarna hitam, putih dan merah sebagai warna identitas PT. Ideal Formica Purnatata, sehingga warna yang ditampilkan terkesan tegas, modern dan sesuai dengan identitas PT. Ideal Formica Purnatata.

\section{Penulisan Naskah}

Pada rancangan media katalog produkpada PT. Ideal Formica Purnatata terdapat unsur-unsur komunikasi grafis seperti teks (tulisan), ilustrasi (foto atau image), warna dan elemen desain. Salah satunya adalah naskah atau teks (tulisan) sebagai headline ataupun subheadline bodycopy yang diperlukan dalam perancangan agar penyampain informasi dapat mudah dimengerti dan tepat sasaran, teks digunakan sebagai judul (headline), sub judul, naskah (body copy), logo (logo type)pada desain media katalog produk ini penulisan naskah diperlukan untuk menginformasikan sebuah produk furnitur yang diproduksi PT. Ideal Formica Purnatata.

\section{Pengarahan Visual}

Warna yang dipilih adalah hitam, putih dan merah. Dengan domain warna putih yang mencirikan identitas PT. Ideal Formica Purnatata. Jenis huruf yang dipakai dalam perancangan diantaranya menggunakan beberapa jenis huruf yang karakternya lebih sesuai dengan desain katalog produk, yaitu:Verdana dan century gothic. Gaya tampilan visual secara grafis ditampilkan dengan nuansa putih sehingga terlihat terang dan menarik dan sesuai dengan identitas PT. Ideal Formica Purnatata.

\section{Proses Desain}

\section{Layout Kasar}

Layout kasar adalah penerapan elemen-elemen desain media yang nantinya akan dipergunakan dalam perancangan media komunikasi visual yang disertai acuan 
standarisasi pada desain yang akan dibuat, umumnya dibuat dengan tampilan hitam putih, dibuat dengan coretan atau sketsa dengan menggunakan pensil gambar. Layout kasar diperlukan, sebagai panduan pada saat proses desain dengan menggunakan aplikasi komputer.Berikut adalah gambar layout kasar proses perancangan media katalog produk furnitur.

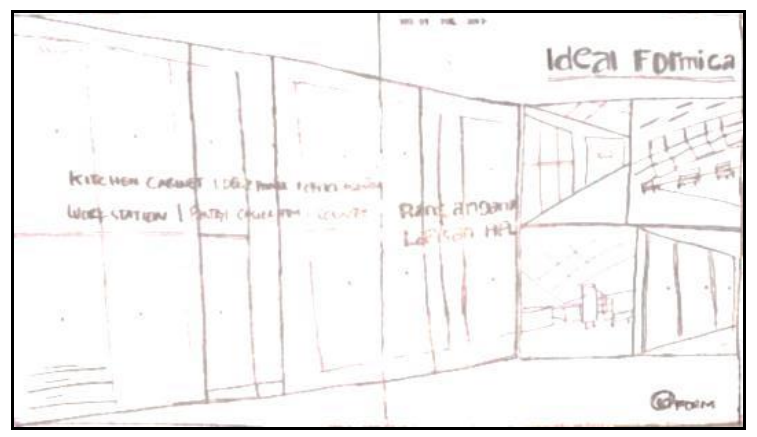

Gambar.1. Layout Kasar Cover depan-belakang katalog

Gambar 1 diatas menggambarkan konsep dalam pembuatan cover depan dan belakang dengan ukuran $42 \times 22.5 \mathrm{~cm}$. Layout kasar cover ini akan melengkapi bagian dari katalog sebagai pembuka.

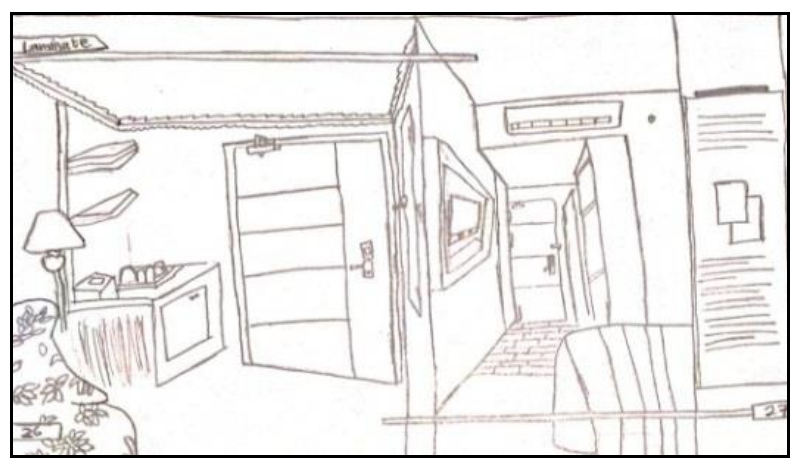

Gambar.2. Layout Kasarkatalog 1

Gambar 2 diatas menggambarkan konsep pembuatan isi dari katalog dengan ukuran $42 \times 22.5 \mathrm{~cm}$. Layout kasar ini akan menjelaskan gambar produk furnitur yang akan di pasarkan.

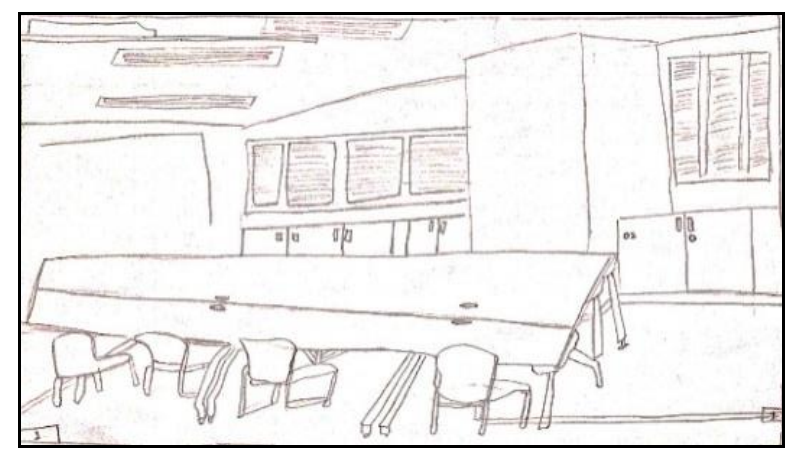

Gambar.3. Layout Kasar katalog 2 
Gambar 3 diatas merupakan konsep pembuatan isi katalog dengan ukuran $42 \times 22.5 \mathrm{~cm}$. Layout kasar ini akan di rancang sebagai penjelesan dari gambar produk furnitur.

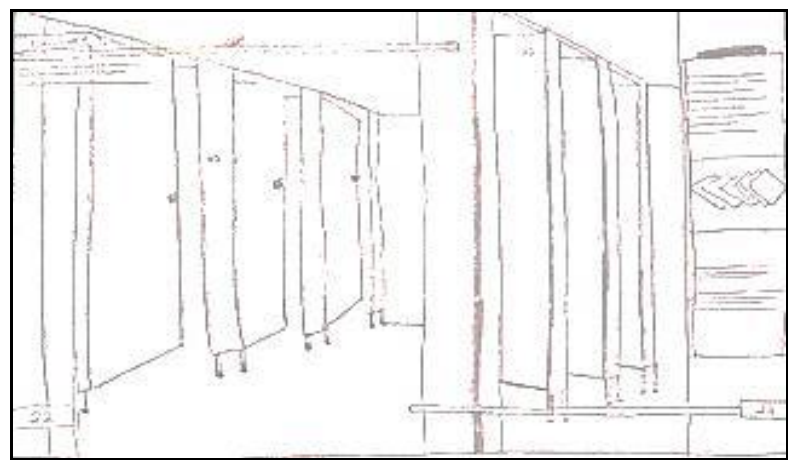

\section{Gambar.4. Layout Kasar katalog 3}

Gambar 4 diatas dibuat sebagai konsep dari isi katalog dengan ukuran $42 \times 22.5 \mathrm{~cm}$. Layout kasar ini di rancang sebagai tahap awal untuk membuat isi dari katalog yang akan menjelaskan setiap produk furnitur.

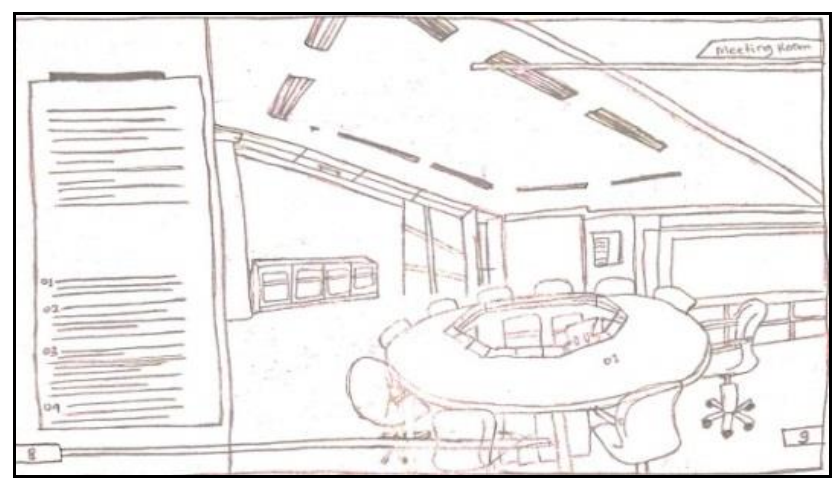

Gambar.5. Layout Kasarkatalog 4

Gambar 5 diatas sebagai konsep isi dari katalog dengan ukuran $42 \times 22.5 \mathrm{~cm}$. Layout kasar ini akan menerangkan semua gambar produk furnitur yang ada di katalog.

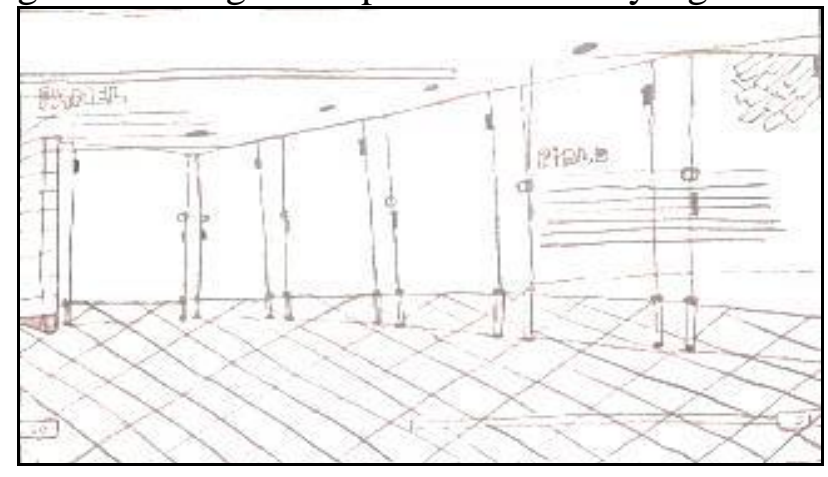

\section{Gambar.6. Layout Kasar katalog 5}

Gambar 6 diatas merupakan konsep pembuatan isi katalog dengan ukuran 42x22.5cm. Layout kasar ini akan menjelaskan gambar dari produk furnitur yang akan dirancang dalam katalog. 


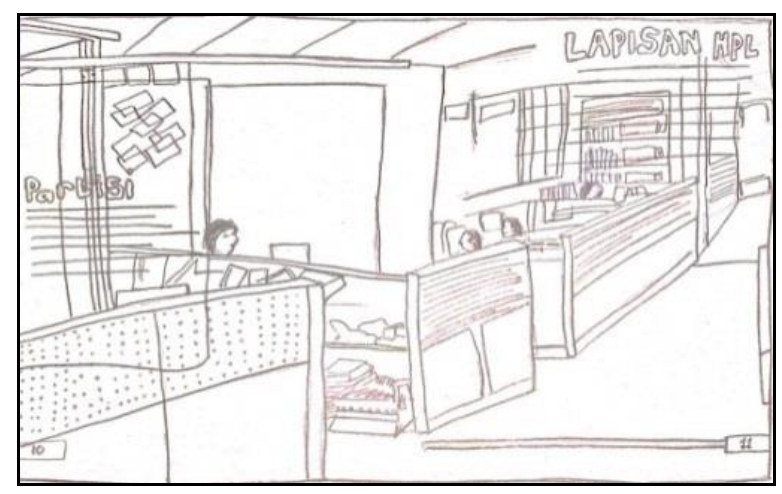

Gambar.7. Layout Kasar katalog 6

Gambar 7 diatas dibuat sebagai konsep dari isi katalog dengan ukuran $42 \times 22.5 \mathrm{~cm}$. Layout kasar ini di rancang untuk menjelaskan produk furnitur yang ada di katalog.

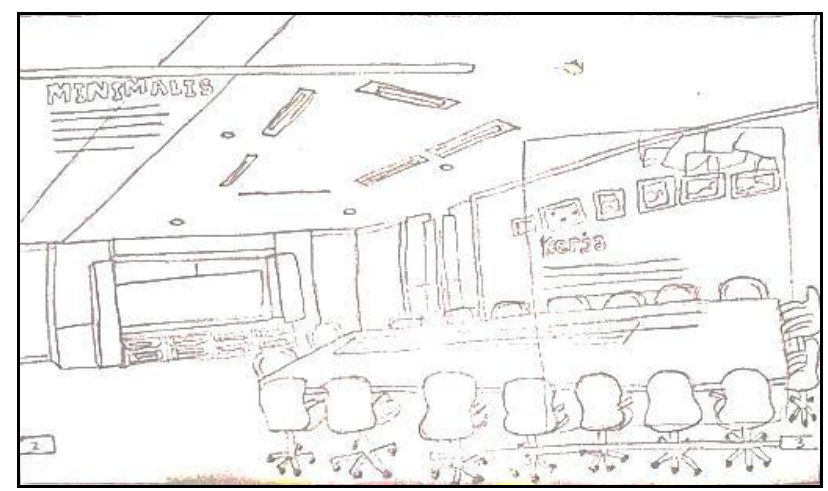

\section{Gambar.8. Layout Kasar katalog 7}

Gambar 8 diatas adalah konsep isi katalog dengan ukuran $42 \times 22.5 \mathrm{~cm}$. Layout kasar ini akan di rancang sebagai gambaran isi katalog yang akan menampilkan semua gambar dari produk furnitur.

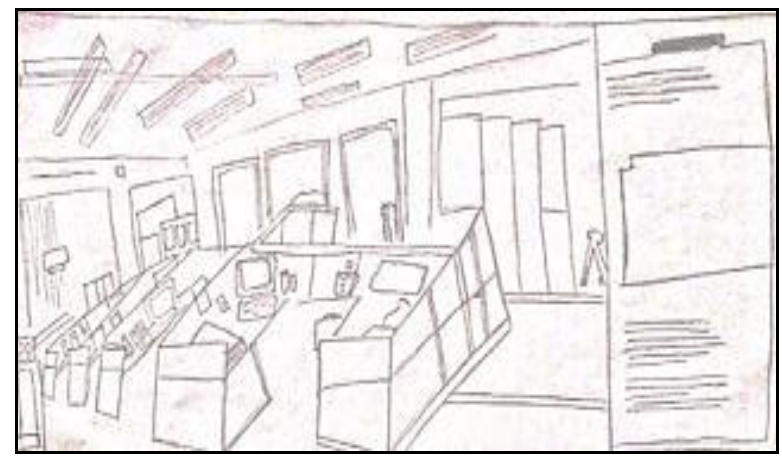

Gambar.9. Layout Kasar katalog 8

Gambar 9 diatas adalah konsep dari isi katalog dengan ukuran $42 \times 22.5 \mathrm{~cm}$. Layout kasar di rancang sebagai gambaran dari isi katalog yang akan di buat.

2. Layout Kompherensif 
Layout kompherensif adalah proses desain yang sudah memasuki tahap komputerisasi dan pewarnaan, namun tahap ini belum selesai seutuhnya, karena masih harus mengalami proses revisi. berikut adalah layout kompherensifmedia katalog produk.

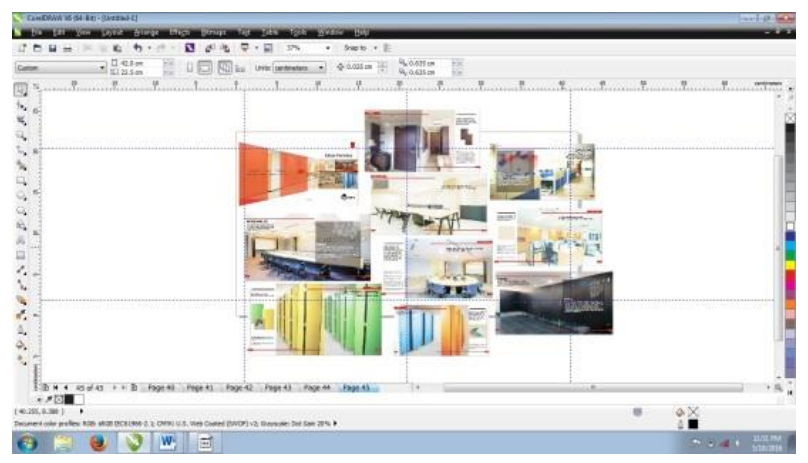

\section{Gambar.10. Layout kompherensif Katalog Produk}

Gambar 10 diatas adalah rancangan katalog yang masih dalam tahap komputerisasi dan pewarnaan, yang nantinya akan menjelaskan isi dari katalog yang mencakup seputar penjelasan produk furnitur.

\section{Final Artwork}

Hasil akhir dari layout kompherensif yang telah diperbaiki, dimana tahap ini merupakan hasil akhir atau finishing, yang kemudian dapat digunakan untuk acuan saat proses produksi. Berikut tahapan proses akhir dari perancangan media kompherensif media katalog produk furnitur.

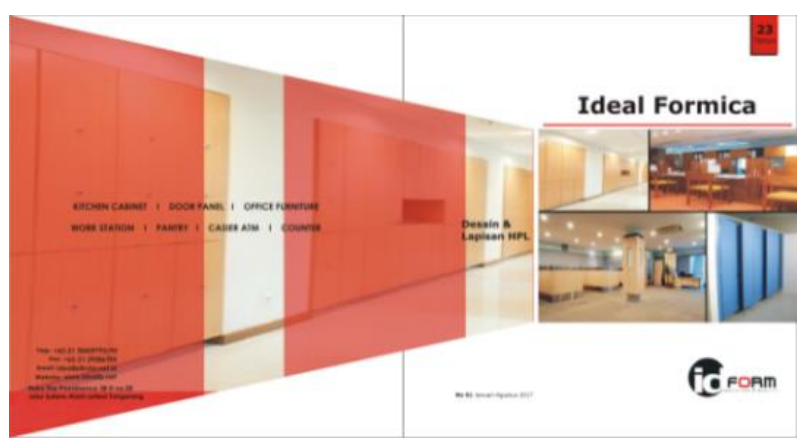

\section{Gambar.11. Final Artwork Katalog Cover depan-belakang}

Gambar 11 diatas menggambarkan hasil akhir yang telah finish berupa cover depan dan belakang ukuran $42 \times 22.5 \mathrm{~cm}$. Dibuat sebagai tahap awal pembuatan katalog. Foto ini di dapat dari proyek perusahaan. 


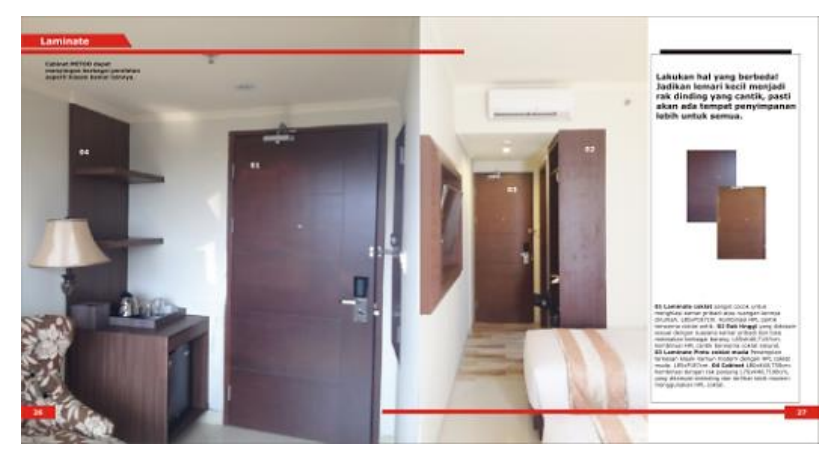

\section{Gambar.12. Final Artwork Katalog 1}

Gambar 12 diatas menggambarkan hasil akhir yang telah finish berupa isi dari katalog dengan ukuran $42 \times 22.5 \mathrm{~cm}$. Digunakan sebagai penyampaian informasi dari isi katalog tentang panel pintu.

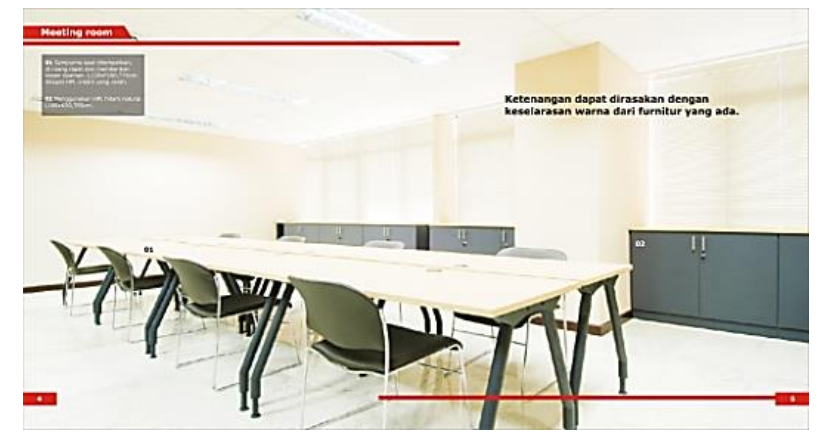

\section{Gambar.13. Final Artwork Katalog 2}

Gambar 13 diatas menggambarkan hasil akhir yang telah finish berupa isi katalog dengan ukuran $42 \times 22.5 \mathrm{~cm}$. Sebagai penyampaian informasi isi katalog tentang meeting room.

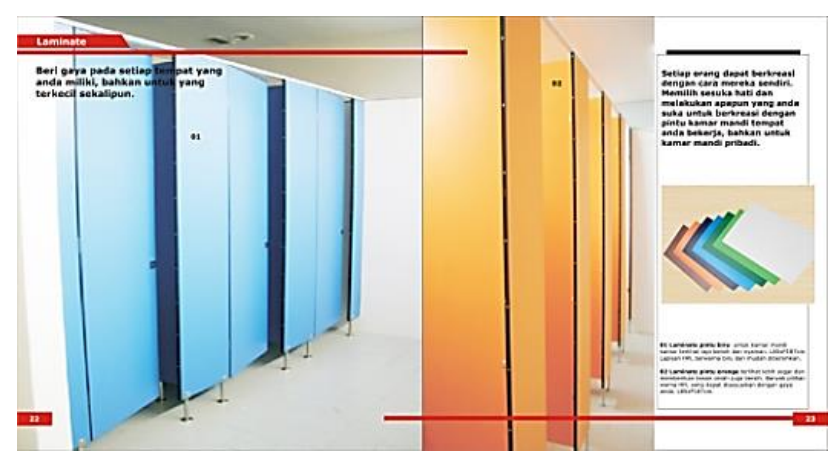

Gambar.14. Final Artwork Katalog 3

Gambar 14 diatas menggambarkan hasil akhir yang telah finish berupa isi katalog dengan ukuran $42 \times 22.5 \mathrm{~cm}$. Sebagai penyampaian informasi isi dari katalog tentang panel pintu. 


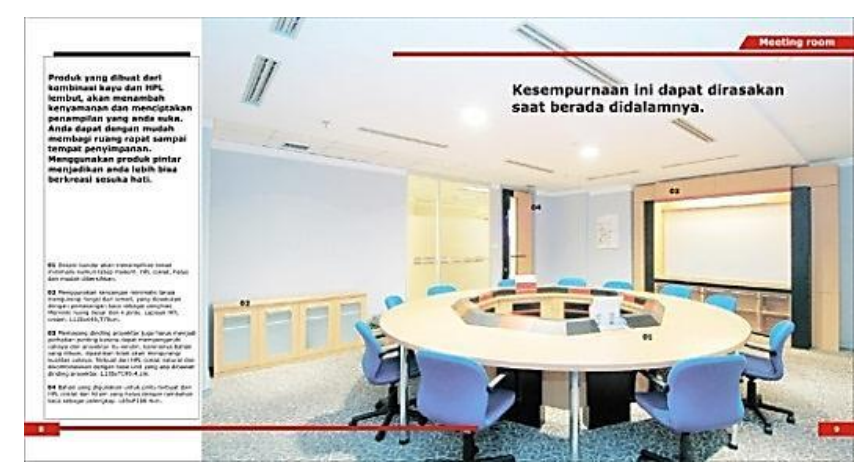

Gambar.15. Final Artwork Katalog 4

Gambar 15 diatas menggambarkan hasil akhir yang telah finish berupa isi katalog dengan ukuran $42 \times 22.5 \mathrm{~cm}$. Sebagai penyampaian informasi isi dari katalog tentang meeting room.

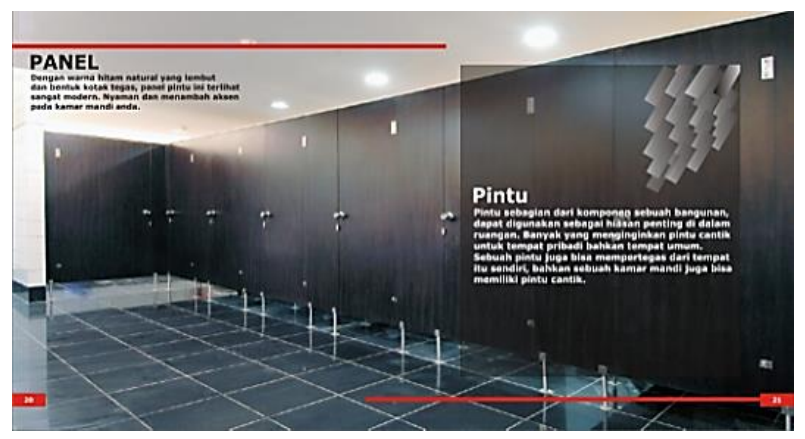

Gambar.16. Final Artwork Katalog 5

Gambar 16 diatas menggambarkan hasil akhir yang telah finish berupa isi katalog dengan ukuran $42 \times 22.5 \mathrm{~cm}$. Sebagai penyampaian informasi isi dari katalog yang menjelaskan tentang panel pintu.

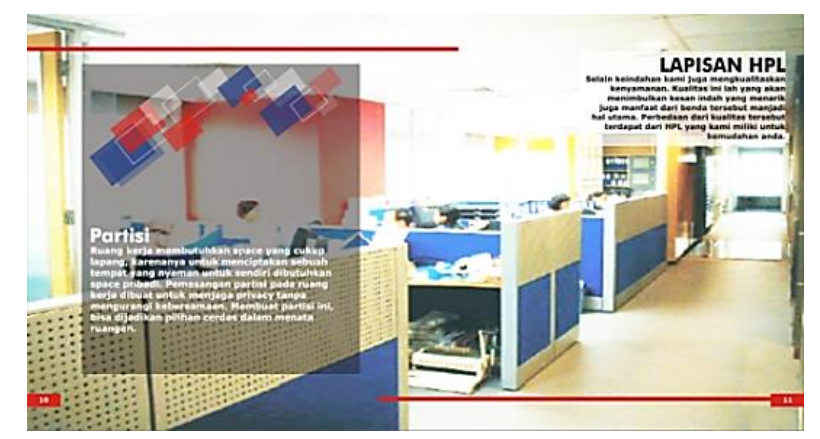

Gambar.17. Final Artwork Katalog 6

Gambar 17 diatas menggambarkan hasil akhir yang telah finish berupa isi katalog dengan ukuran $42 \times 22.5 \mathrm{~cm}$. Isi dari katalog tentang Partisi. 


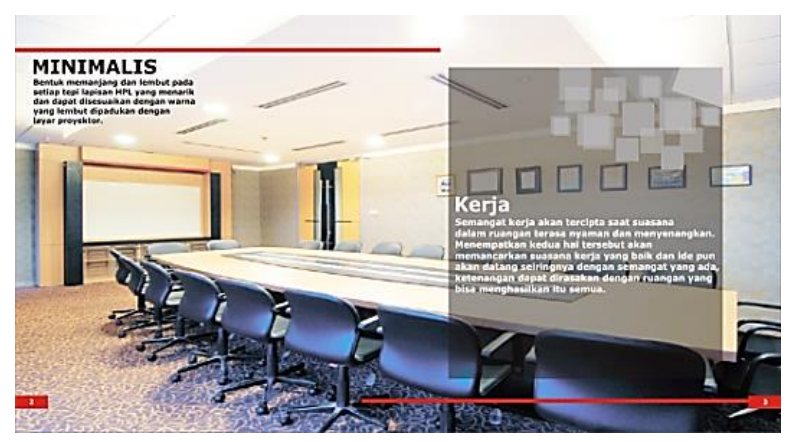

Gambar.18. Final Artwork Katalog 7

Gambar 18 diatas menggambarkan hasil akhir yang telah finish berupa isi katalog dengan ukuran $42 \times 22.5 \mathrm{~cm}$. Untuk menyampaikan isi dari katalog tentang meeting room.

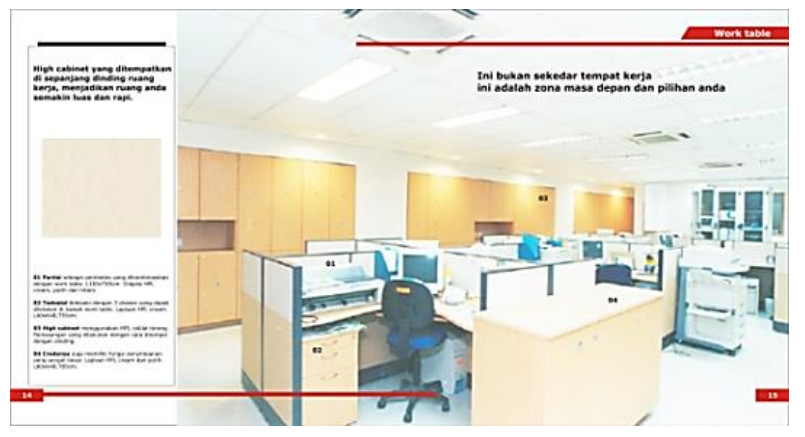

Gambar.19. Final Artwork Katalog 8

Gambar 19 diatas menggambarkan hasil akhir yang telah finish berupa isi katalog dengan ukuran $42 \times 22.5 \mathrm{~cm}$. Sebagai sarana informasi dari isi katalog berupa work table.

\section{KESIMPULAN}

Media komunikasi visual dalam menyampaikan sebuah promosi dan informasi sangat penting dan bermanfaat dalam memperkenalkan citra/ image suatu instansi. PT. Ideal Formica Purnatata kali ini akan menggunakan media katalog produk furnitur. Media ini di pilih karena dapat menunjang promosi dan informasi produk yang di produksi oleh PT. Ideal Formica Purnatata dan diharapkan dapat meningkatkan penjualan setiap tahunnya. Karena media katalog produk yang ditampilkan sangat menarik, informasinya up to date dan jelas, sehingga mudah dipahami oleh konsumen yang membacanya. Dalam desain ini juga sudah mencakup semua informasi yang dibutuhkan konsumen untuk mengetahui isi dari setiap produk yang dipasarkan.

\section{DAFTAR PUSTAKA}

[1] Akbar, Rizall Safiyuddin. 2013. Perancangan Media Komunikasi Visual Katalog sebagai Sarana Promosi Rvins Jeans. Jakarta: Mercu Buana.

[2] Budiarto, Mukti, Yohanes Ari Kuncoro Yakti, Maimunah, Lusyani Sunarya. 2011. Desain Media Komunikasi Visual sebagai Penunjang Kegiatan Promosi Kampus. Jurnal CCIT Vol.1 No.2. Tangerang: Perguruan Tinggi Raharja.

[3] Daryanto. 2011. Administrasi Pendidikan. Jakarta: Rineka Cipta. 
[4] Fawzia, Marsya. 2012. Pengetahuan Konsumen Tentang Katalog Oriflame sebagai Media untuk Memasarkan Produk. Surabaya: Universitas Airlangga.

[5] Hakim, Fitro Nur, Achmad Solechan, Migunani. 2015. Perancangan Katalog Digital pada UMKM Sentra Bordir Desa Padurenan Kudus. Journal Informatika UPGRIS Vol.1, No.2, Semarang: STMIK Provinsi Semarang.

[6] Hidayah, Nur Afni. 2014. Perancangan Media Seni Grafis sebagai Media Promosi Jurusan Seni Rupa FBS UNNES. Semarang: Universitas Semarang.

[7] Maimunah, Lusyani Sunarya, Nina Larasati. 2012. Media Company Profilesebagai Sarana Promosi dan Informasi. Journal CCIT Vol.5 No.3. Tangerang: Perguruan Tinggi Raharja.

[8] McLeod, Raymond. 2012. Sistem Informasi Manajemen. Jakarta: Salemba Empat.

[9] Munawar, Jaelani. 2013. Perancangan Media Desain Katalog Produk di PT Utama Mandiri Jaya. Tangerang: Perguruan Tinggi Raharja.

[10] Palupi, Bram Bramanto. 2014. Perancangan Media Komunikasi Visual Berbentuk Katalog Produk sebagai Media Promosi di PT Anugerah Duta. Tangerang: Perguruan Tinggi Raharja.

[11] Prasetyo, Handoyo Ade. 2013. Perancangan Katalog Online Berbasis Website sebagai Media Promosi danInformasi Pada Twenty One Computer. Yogyakarta: AMIKOM Yogyakarta.

[12] Rahardja, Untung, Hidayati, Mia Novalia. 2011. Peningkatan Kinerja Distributed Database Melalui Metode DMQ Base Lavel.Journal CCIT Vol.4 No.3. Tangerang: Perguruan Tinggi Raharja.

[13] Satrio, Putra Uji Deva, Sarjono, Mohamad Sigit. 2012. Perancangan Katalog Wisata Kota Surabaya sebagai Media Informasi Massa. Journal UM Vol.1, No.1, Malang: Universitas Negeri Malang.

[14] Sumaryani, Asih. 2014. Perancangan Media Katalog sebagai Penunjang Informasi Dan Promosi Pada Cv.Zero Store. Tangerang: Perguruan Tinggi Raharja.

[15] Sunarya, Lusyani, Mukti Budiarto, Jasmine Dara Assyifa. 2015. Keefektifan Media Komunikasi Visual sebagai Penunjang Promosi pada Perguruan Tinggi Raharja, Journal CCIT Vol. 9 No. 1, Tangerang: Perguruan Tinggi Raharja.

[16] Sunarya, Lusyani. Radiyanto. Erna Susanti. 2013. Enriching Company Profile sebagai Penunjang Media Informasi dan Promosi pada Perguruan Tinggi Raharja. Journal CCIT Vol. 7 No. 1. Tangerang: Perguruan Tinggi Raharja.

[17] Suprian, Risman Yulianto. 2012. Perancangan Aplikasi Katalog Interaktif sebagai Media Promosi pada Butik Busana Sunnah Banjarmasin Berbasis Multimedia. Yogyakarta: STMIK Yogyakarta.

[18] Tinarbuko, Sumbo. 2015. DEKAVE (Penanda Zaman Masyarakat Global). Yogyakarta: CAPS. 